\title{
The need for a new model of the physician-patient relationship: a challenge for modern medical practice
}

ANTOINE AOUN ${ }^{1, E}$, F, SIBELLE AL HAYEK ${ }^{1, E, F}$, FLORA EL JABBOUR ${ }^{2, E, F}$

${ }^{1}$ Faculty of Nursing and Health Sciences, Notre Dame University - Louaize, Zouk Mosbeh, Lebanon

${ }^{2}$ Independent research fellow

A - Study Design, B - Data Collection, C - Statistical Analysis, D - Data Interpretation, E - Manuscript Preparation, F - Literature Search, G - Funds Collection

Summary A revolution in the field of medicine, enhancing knowledge and techniques, has been affecting, for the last fifty years, al aspects of healthcare, bioethics and finance. It is in this new context that we should relocate the physician-patient relationship and identify the different form that it is currently taking. The aim of this review paper is to evaluate the different models of the physician-patient relationship, described in medical literature, and to emphasize the need for an innovative interaction that fits the new dimensions of modern medical practice. During the last decade, the debate has grown around the opposition between several patterns of the physician-patient relationship. The model of mutual participation of Szasz and Hollender (involving a relationship set between equals and built on helpfulness) and the deliberative model of Emanuel and Emanuel (encouraging the patient's independence in decisionmaking, which occurs after the physician's helpful advice) were considered appropriate models of the physician-patient relationship, with several limitations. In modern medicine, patients have an increasing number of needs that have to be satisfied: personal and familial, psychological and social, material and spiritual. The physician is rarely adequately prepared for the new needs and the new dimensions of the current physician-patient interaction.

Key words: personal autonomy, knowledge, decision making, patient participation, patients, physicians.

Aoun A, Al Hayek S, El Jabbour F. The need for a new model of the physician-patient relationship: a challenge for modern medical practice. Fam Med Prim Care Rev 2018; 20(4): 379-384, doi: https://doi.org/10.5114/fmpcr.2018.79351.

\section{Background}

A recent revolution in the field of medicine has been affecting all aspects of healthcare. The physician-patient relationship has always been facing challenges, which has sparked heated debate on the ideal physician-patient relationship.

In his book on the history and the evolution of the physician-patient relationship, Bernard Hoerni distinguishes three significant time periods [1]:

- $\quad$ Aside from Plato, who insisted on the necessary relation of confidence that should be established between the patient and his physician, and from the Hebraic Talmud, where resorting to the patient's consent is mentioned for the first time in recorded history, traditional medicine, from Hippocrates up until the eighteenth century, applies the paternalistic (parent-child) pattern by maintaining the patient in a position of obedience to his physician.

- The eighteenth century is marked by defending the individual's rights to life and liberty (Hobbes, Locke, Stuart Mill, Rousseau, Kant, etc.), heralding the era of patient autonomy. But the development of physiology, hygiene and preventive medicine, in the nineteenth century, contributed to reinforcing a medical authority that prevented the notion of patient autonomy from practically gaining ground.

- It is only in the second half of the twentieth century, under the influence of mainly North American philosophers (Greenspan, Rawls, Nozick, Maclntyre, Rorty, etc.), sociologists, jurists and physicians, that patient autonomy started to become gradually imposed through laws and rights. Bioethics, developed in this era, was much more a marker than an engine to the evolution of the physician-patient relationship. As a sign of this evolution, many codes of deontology, professional charts and boards of ethics emerged in the Western world.

The exponential scientific evolution of medicine, and the necessary effort to deepen the scientific knowledge expected from physicians, seem to have, with time, dragged the human dimension of medicine adrift. Contact with the patient as a human being is gradually vanishing from a large portion of hospital services and even in ambulatory care. It is giving way to technical innovations and advances in cybernetics, which take the patient in charge starting from the diagnosis phase, up to the administering of care, and even through the long-term follow-up phase. The relationship of confidence between two human beings (the patient and the physician) is no longer the guiding thread for the path of treatment and, eventually, recovery; it has been almost entirely replaced with technical progress and scientific rigor, which are nonetheless excellent in some respect [2]. Medicine is not only a science; it is an art, a cultural reality that entails intersubjectivity. It currently tries to rely on science, but healing cannot be accomplished solely through the cold rationality of science. Furthermore, scientific rigor is not applied unbiasedly throughout the entire medical process, for it involves industrial and commercial interests motivated by profit. Hence, patients who are most dispossessed of their bodies on the symbolic level are questioning the competence of their physicians. Thus, there is a surge in frequency regarding the number of lawsuits against physicians.

To conclude, we would like to highlight the words of Teresa Hellin: "To attend those who suffer, a physician must possess not only the scientific knowledge and technical abilities, but also an understanding of human nature. The patient is not just a group of symptoms, damaged organs and altered emotions. 
The patient is a human being, at the same time worried and hopeful, who is searching for relief, help and trust. The importance of an intimate relationship between patient and physician can never be overstated, because in most cases, an accurate diagnosis and an effective treatment rely directly on the quality of this relationship" [3].

What type of physician-patient relationship do we then need to promote after this medical revolution, whose consequences are increasingly manifest? The ancient paternalistic approach to this relationship obviously no longer meets the expectations of today's individual, nor does it contribute to the enhancement of his overall health [4].

The difficulties and challenges facing the physician-patient relationship in Lebanon, a Middle Eastern country of cultural diversity, are what motivated us to write this review. The aim of this paper is to evaluate the different models of the physician-patient relationship described in medical literature and to emphasize the need for an innovative interaction that fits the new dimensions of modern medical practice.

\section{The three basic models of Szasz and Hollender (Table 1)}

Szasz and Hollender (1956) proposed three possible models of the physician-patient relationship $[5,6]$ :

(a) The model of activity-passivity: fully paternalistic, analogical to the parent-infant relationship, where the physician is active and the patient, passive. This model is based on the physician's dominance, since the patient is not given the right to partake in decision-making, thus he relies on the physician's medical treatment, which is "irrespective of the patient's contribution and regardless of the outcome" $[5,6]$. In other words, this model does not involve an effective interaction between the patient and the physician. This situation empowers the physician, and "in this way, it gratifies his needs for mastery and contributes to his feelings of superiority" [7]. (b) The model of guidance-co-operation: used in non-severe medical situations. When the patient is sick, he might, out of worry, want to take care of himself. This prepares him for cooperating with the physician. This act keeps the physician in a situation of power, where he directs the patient and expects compliance to his instructions. This model is analogically similar to the relationship between a parent and his adolescent offspring $[5,6]$.

(c) The model of mutual participation (also advocated by Balint (1965)): describes a relationship set between equals and built on helpfulness $[5,6]$. The interaction between the patient and the physician should be set at equal strength, freedom and gratification. This allows the patient to pay attention to his health, especially in the case of chronic diseases, where his awareness and understanding of his condition, and of the treatment he is undergoing, are essential to success. Therefore, the physician's gratification results from the help he offers to the patient, rather than from his dominance over the patient [3].

\section{The four models of Emanuel and Emanuel}

\section{(Figure 1, Table 2)}

Almost 60 years ago, the typical relationship between the patient and the physician was theorized as paternalism; in other words, the physician used to make the decision regarding the treatment without the patient intervening. As of 1960, this relationship was no longer favored, which led to controversy regarding the ideal model - of the physician-patient relationship - that would best suit the patient [8].

\section{Paternalistic Deliberate Interpretive Informative (Low Autonomy/ (High Autonomy/ Low Values High Values}

Figure 1. Patient autonomy and patient values in the Emmanuel and Emmanuel Model [9]

\begin{tabular}{|l|l|l|l|l|}
\hline Table 1. Three basic models of the doctor-patient relationship (adaptation from Szasz and Hollender [5, 6]) \\
\hline Model & Physician's role & Patient's role & $\begin{array}{l}\text { Clinical application of } \\
\text { model }\end{array}$ & Prototype model \\
\hline Activity-passivity & Totally active & Totally passive & $\begin{array}{l}\text { Anesthesia, acute trauma, } \\
\text { coma, delirium, etc. }\end{array}$ & Parent-infant \\
\hline $\begin{array}{l}\text { Guidance- } \\
\text { co-operation }\end{array}$ & $\begin{array}{l}\text { Initiator (tells patient } \\
\text { what to do) }\end{array}$ & $\begin{array}{l}\text { Co-operator (provides } \\
\text { consent) }\end{array}$ & $\begin{array}{l}\text { Acute infectious pro- } \\
\text { cesses, etc. }\end{array}$ & Parent-adolescent \\
\hline Mutual participation & $\begin{array}{l}\text { Helps patient to under- } \\
\text { stand his illness and thus } \\
\text { help himself }\end{array}$ & $\begin{array}{l}\text { Participant in "partner- } \\
\text { ship" (uses expert help) }\end{array}$ & $\begin{array}{l}\text { Most chronic psychiatric } \\
\text { disorders }\end{array}$ & Adult-adult \\
\hline
\end{tabular}

Table 2. Framework for classification of patients in terms of degrees of autonomy, formation of care-related values and extent of medical information [3]

\begin{tabular}{|l|l|l|l|l|}
\cline { 2 - 5 } \multicolumn{1}{l|}{} & $\begin{array}{l}\text { High level of medical } \\
\text { information }\end{array}$ & $\begin{array}{l}\text { Moderate level of } \\
\text { medical information }\end{array}$ & \multicolumn{2}{l|}{ Low level of medical information } \\
\cline { 2 - 5 } & High autonomy & Moderate autonomy & Low autonomy & No autonomy \\
\hline $\begin{array}{l}\text { Very well-formed healthcare } \\
\text { values }\end{array}$ & Informative & & & \\
\hline $\begin{array}{l}\text { Moderately well-formed } \\
\text { healthcare values }\end{array}$ & Interpretive & & \\
\hline $\begin{array}{l}\text { Few well-formed healthcare } \\
\text { values }\end{array}$ & & & Deliberative & Paternalistic \\
\hline $\begin{array}{l}\text { No well-formed healthcare } \\
\text { values }\end{array}$ & & & & \\
\hline
\end{tabular}


Emmanuel and Emmanuel (1992) described the physician-patient relationship through a four-part division: paternalistic, deliberative, interpretive and informative. These models are the ones that were studied the most. They differ in structure; their difference being mainly based on two parameters: the patient's values and the patient's autonomy. In all four models, the first step consists in the physician revealing to the patient the medical treatment he intends to administer. Briefly, in the paternalistic model, the physician makes the decision, and the patient simply obeys him. In the interpretive model, the physician allows the patient to explain his point of view and helps him in choosing the best treatment; however, he is not allowed to impose his decision upon the patient. In the informative model, the patient is free to choose the treatment that best suits him, without being reprimanded by the physician. In the deliberative model, the patient is allowed to give his opinion, though the physician has the authority to force the patient into obeying his decision [9].

\section{(a) Paternalistic model}

In the paternalistic model, the patient is not actually aware of the important details of his medical situation, so the physician directly decides on the treatment that should be initiated, after briefly informing the patient about his case. The physician identifies the disease according to his diagnosis and then selects the treatment based on his medical knowledge and expertise. He then obliges the patient to follow his instructions. There is no real interaction between the patient and physician here, since the latter considers that he is providing the former with the best treatment, thus the patient should accept the intervention regardless of his own point of view. The physician acts as the patient's guardian, since he believes that he can make the correct lifesaving decision, and the patient can only comply [9].

In the past, this model was applied in the case of patients presenting acute medical disorders which place them in a situation of great dependence. At the same time, the therapeutic efficiency was modest, and the options of the physician were limited. Many factors nowadays contribute to rendering this model obsolete:

- The patient is no longer a passive individual who hands over entirely to the physician the responsibility of the decision that concerns the treatment he will be receiving. Having more and more access, through different media, to information on health and diseases, and to the latest medical breakthroughs, he asks the physician to keep him informed of all the different aspects of his medical condition (symptoms and their interpretations, test results, etc.) and to allow him to partake in the decision-making process concerning the diagnosis and the treatment of the disease. This request is highly justified, since medical explorations and treatments are not risk-free.

- Many different therapeutic paths can be recommended for the treatment of a disease. Therefore, deciding on one of them does not only depend on the biomedical criteria determined by the physician; the decision can thus be made after concertation with the patient.

- This is all the more true since we live in a society open to pluralism of opinions: the physician can no longer impose on the patient his vision of what is right for the patient.

Yet, the paternalistic pattern is not dead. It still inspires, openly or hypocritically, the attitude of many treating physicians. Still, it is true that, in a definite number of circumstances (minors, legally incapacitated persons, medical emergencies), the patient's consent and, a fortiori, his contribution to the medical decision-making process are difficult to implement [10]. This model is therefore still recommended in severe cases, such as acute care and trauma care, where immediate action should be taken [9].

(b) Informative model

The informative model is referred to as the scientific, engineering or consumer model [11]. In this model, the physician explains to the patient all the different aspects of the disease, and then he recommends several treatments by pointing out the risks and benefits of each, based on his expertise and the medical information (symptoms, test results, etc.) at hand. The patient here understands the physician's explanations, and after further clarifications, he is given the freedom to choose the intervention he deems best for him.

In other words, in the informative model, the physician helps the patient by supplying him with the adequate medical information, and the patient has the freedom to decide upon the treatment he sees fit, since he already has sufficient medical knowledge regarding his condition [9].

This model refers to an ethical paradigm where the freedom of the patient and his right to self-determination have to be respected and prioritized. The ultimate moral principle here is not only focused on doing what is beneficial to the patient's health, it is also concerned with respecting his freedom and his dignity as a person who makes his own decisions about matters that concern him - under the cover of a contract between equals [12].

The informative physician is forbidden to force his decision on the patient, since it contradicts the latter's freedom of making decisions [13]. He must be a highly trained and expert physician who provides particular and elaborated interventions. This confirms specialization and impersonalization in the medical field.

The informative model assumes that patients have fixed values and desires. However, people are doubtful of what they want. Unlike animals, humans have "second order desires" [14, 15], which means that they tend to change their preferences and demands. The ability to change what we want requires a process of moral deliberation, where other people who understand us can indicate to us how we should be and make us accept the situation we are in. Self-reflection has no important function in the informative model, although changes in health may alter a person's preferences $[16,17]$.

\section{(c) Interpretive model}

In the interpretive model, the patient has incomplete knowledge about his situation, so the physician acts as a counselor by providing him with medical information. The patient then makes the decision after a discussion with the physician [9].

As in the informative model, the interpretive physician identifies the disease and provides the patient with information related to the medical intervention. Moreover, the physician tries to identify the patient's values and then decides upon the intervention that best fits with them. Thus, the physician must visualize the patient's entire life as a story in order to clarify the patient's values $[16,17]$. Consequently, the physician proposes the intervention without forcing the patient to choose one treatment over another. It is up to the patient to decide which treatment best suits his values. For this model, the concept of autonomy (applied to the patient) is fundamental and refers to self-understanding. In other words, the physician helps the patient understand himself and his identity, so that the patient can freely decide upon the medical intervention that matches his values.

Some objections to the interpretive model were raised. In several cases, this model can be similar to the paternalistic model. Since physicians may have restricted skills and time, they might involuntarily enforce their own values instead of understanding the patient's values.

Additionally, the concept of autonomy as self-understanding does not force the patient to foster values different from his own. Hence, the options the physician can recommend then become limited, for they should not contradict the patient's values. However, in some medical cases, the physician urges the patient to accept a certain intervention (e.g. patients with high cholesterol levels are highly recommended to follow a healthy dietary lifestyle; patients with HIV are forced to have protected 
sex). The interpretive model will never represent the ideal physician-patient relationship as long as the evaluated judgments are eliminated.

\section{(d) Deliberative model}

In the deliberative model, the physician identifies the medical situation of the patient and tries to find the adequate intervention. His aim is to convince the patient of following one specific treatment rather than any other. The discussion between the patient and the physician is professional, which means that the conversation is only about health-related issues and values related to the medical case. The physician here only provides his opinion on the intervention he selected, without forcing the patient into accepting it. After the patient agrees on an intervention, both the patient and the physician assess the importance of health-related values. The physician's role is not only to propose interventions that the patient could undergo, but also to teach him about the medical therapy he should adopt, thus acting as a friend and a teacher. The concept of autonomy in this model promotes moral self-development, since the patient's role is not only to follow certain rules, but also to suggest health-related practices and value their importance regarding the intervention $[18,19]$.

In other words, the physician communicates with the patient in order to identify the patient's core values and elaborate upon them. After the health assessment, the physician tries to convince the patient of his decision [9].

Since our societies share a variety of different experiences and values, the physician-patient model should not be uniformized and generalized. Some believe that no model should be prioritized [20]. In reality, no actual physician-patient relationship is perfectly identical to the theorized form of the model that it represents, yet the preferred model should be the deliberative one, since it encourages the patient's independence in making decisions, which occurs after the physician's helpful advice.

An advantage of the deliberative model is that it includes beneficence. The principle of beneficence consists of three key elements, as described by William Frankena: [21] “(1) One ought to prevent evil or harm. (2) One ought to remove evil or harm. (3) One ought to do or promote good". The deliberative model differs from other models in that it strongly encourages healthy assessment. Physicians have the right to convince the patient of letting go of whatever is harmful to him. For example, if the patient is in a situation harmful to himself (e.g. poor diet, high drug consumption, etc.), the physician can intervene by proposing a better and healthier choice, thus preventing harm (further damage caused by self-destructive practices), removing harm (actually ceasing the destructive habits) and promoting good (healthier practices to be adopted in the future). Beneficence highly emphasizes communication. It is characterized by a two-way communication between the physician and the patient regarding values and treatment. Whenever there is a strong communication between the patient and the physician, patients would be "less likely to misinterpret the information they receive, more willing to ask for clarification when information is unclear, and quicker to call if symptoms fail to resolve" [22]. This communication can hinder any health-related harm. The deliberative model should be adopted, since it promotes the three bioethical principles of autonomy, beneficence and non-maleficence (the obligation not to harm). The deliberative model incarnates the concept of autonomy, which is not only about making decisions independently and according to one's values, but also about choosing one's values independently.

Several objections to the deliberative model were expressed:

- The first flaw of the deliberative model is that physicians do not really agree upon the same most important health-related values that must be conveyed to their patients. In a pluralistic society, people possess various values, and what a physician may consider as an important value for his patient, another physician may not.

- The second flaw is that moral deliberation will result in interventions that are based on the physician's values. However, the recommendations given to the patient should not be based on the patient's or the physician's values, but on scientific evidence. One bioethicist actually says: "The hand is broken; the physician can repair the hand; therefore, the physician must repair the hand - as well as possible - without regard to personal values that might lead the physician to think ill of the patient or of the patient's values, etc. At the level of clinical practice, medicine should be value-free in the sense that the personal values of the physician should not distort the making of medical decisions" [23].

- The third flaw is that this model is not ideal for the physician-patient relationship, since the patient's aim in visiting a physician is to be treated and not to review his own values. The deliberative model can turn out to be an unintended paternalistic model.

\section{New dimensions}

Nowadays, the diversity of populations worldwide, as well as the continuous development in medicine, are highly affecting the physician-patient interaction. However, the physician-patient models currently used by academics to teach medicine are not efficient enough in bringing attention to all the previously mentioned challenges; therefore, they are striving for a new interaction that fits modern medical practice [24].

The Emanuel and Emanuel system connects the patient's values, autonomy and the advice given by the physician to the patient. These three factors are interdependent, and thus an alteration in one instantly affects the other two. For this reason, the paternalistic model is characterized by low patient values, low autonomy and low medical information provided by the physician, whereas in the informative model, these three factors are high.

Charles et al. consider that the interaction between the patient's autonomy and the medical information, along with other variables, is always continuous. The Emanuel and Emanuel concept states that these variables change uniformly simultaneously, in the sense that when one increases, the others follow similarly [25]. Bradley et al. created a model in which they show the impact of family members on the decision that is finally taken; therefore, this factor becomes a central variable [26]. Humphrey et al. developed a model combining the physician's reflection and the patient's cooperation [27]. Others have inspected the effect of the seriousness of the case on this cooperation and also examined the interaction between cognitive, emotional and reflective demands during the clinical meeting [28, 29].

Since medicine has changed nowadays, young physicians are finding difficulties in applying the old physician-patient relationship to the current medical situation. A new model of the physician-patient interaction should be developed to explicitly address these problems.

In the past, patient autonomy and the revelation of medical information by the physician were tightly linked, because the patient's knowledge in medicine was generally minimal. However, this link does not describe all patients nowadays who are:

- Highly educated in fields other than medicine and have low intimacy with health-related issues yet high autonomy.

- Highly knowledgeable regarding health yet having low autonomy.

- Highly knowledgeable regarding health yet having a low level of information regarding his/her rare and very complicated disease.

A suggested model of the physician-patient relationship in these cases would be to take each patient independently and 
Patient Autonomy

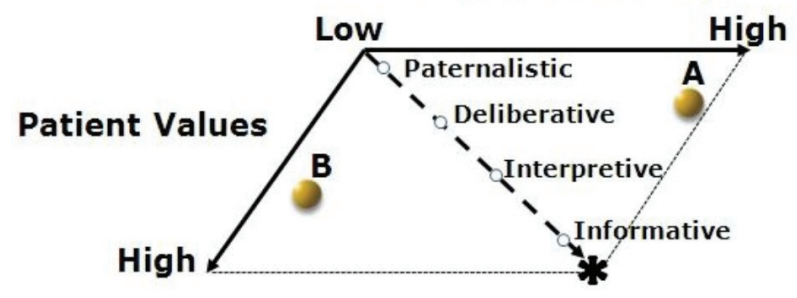

Figure 2. A reinterpretation of past models. In past models patient values and patient autonomy have often been tightly linked. These models assume that as the formation of values increases, autonomy must as well, when in fact these variables may not always co-vary. As described in the text, many patients fall away from this diagonal line. Examples of this include: A, the patient with high levels of autonomy and relatively unformed healthcare-related values, for example a financial analyst, and $B$, the patient from a very traditional culture where health care-related values are clear, but personal autonomy is low [31]

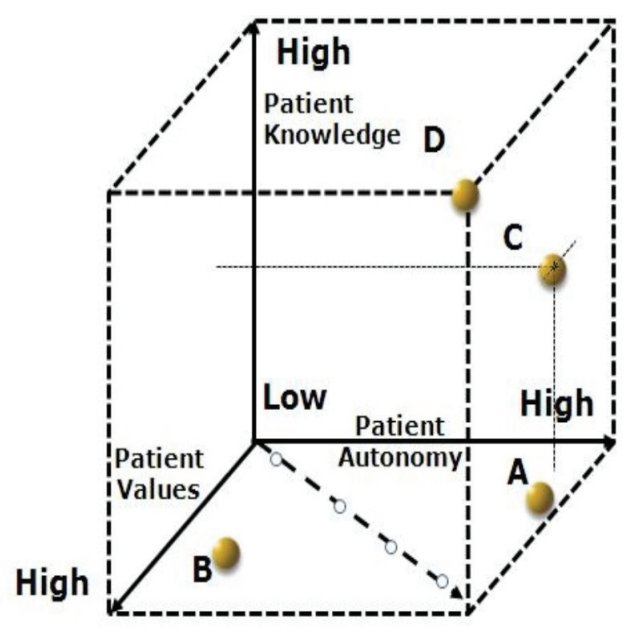

Figure 3. Values, autonomy and information on patient care. Patient values, patient autonomy and patient knowledge are the three axes in this model, which emphasizes both their independence and interaction. Also included is the "Emanuel and Emanuel Reduced Axis", which implies a mutual variability in patient autonomy and values, and where plotted examples $(A, B, C, D)$ highlight the necessity of stepping away from the simplifications implied by past models. A and B: the same as in Figure 2; C: patients may be selectively well-informed about specific diseases; D: Very well-informed patient such as a sick physician [31] evaluate, as variables, his levels of autonomy, health values and medical knowledge. This proposed model could also show the interaction between autonomy, the patient's health values and his medical knowledge (Figure 2 and 3) [30].

\section{Conclusion and practical implications}

Whether it is about facing dependency, a handicap or the end of life, or about managing a chronic illness, debilitating affectation or material difficulties, the patient demands from the treating physician an accompaniment for which the latter is rarely adequately prepared. Many medical cases can neither be treated by means of scientific knowledge, nor by referring to listed processes, but only through empathy, common sense and the ability to advise.

In practical situations, the principle of beneficence (that underlies the paternalistic pattern) and the principle of the respect of autonomy (that underlies many other patterns) should be more complementary than contradictory, and the physician-patient relationship has to associate other values to responsibility (exalted by the paternalistic model) and freedom (which has priority in other models) [19].

Reserving moral and medical decision-making powers to the patient alone does not characterize the ideal physician-patient relationship, a relationship that should be based on shared resolutions and built through "mutual participation and respect" [10].

The physician's job is to help the patient understand the medical situation and available courses of action, and the patient conveys his or her concerns and wishes [10].

The "best path" is certainly not a path of compromise; it is a path of demanding research. The physician-patient relationship should be established on the search for a truthful discourse that transcends the monologue of the knowledgeable who informs the non-knowledgeable, and the "dialogue" that is established between a physician who asks questions and a patient who answers (in this "dialogue", the interrogator continues to dominate the interrogated). The "best path" is achieved when physicians and patients search together for a way out. It is an act of trust between one and another, an inter-personal investment that moves the physician and the patient, who both take the risk of being led, by a truthful discourse, to a place they could not initially have imagined they would reach.

Acknowledgements. The authors would like to thank Dr. Charbel El Amm, who helped in editing the manuscript. They would also like to thank Dr. Dany Daham for his guidance and assistance.

Source of funding: This work was funded by the authors' own resources. Conflicts of interest: The authors declare no conflicts of interest.

\section{References}

1. Hoerni B, ed. L'autonomie en Médecine: nouvelles relations entre les personnes malades et les personnes soignantes. Paris: Firmin Didot Publisher; 1991.

2. Murphy J, Chang H, Montgomery JE, et al. The quality of physician-patient relationships. Patients' experiences 1996-1999. J Fam Pract 2001; 50(2): 123-129.

3. Hellin T. The physician-patient relationship: recent developments and changes. Haemophilia 2002; 8(3): 450-454.

4. Chin JJ. Doctor-patient relationship: from medical paternalism to enhanced autonomy. Singapore Med J 2002; 43(3): 152-155.

5. Siegler M. The progression of medicine: from physician paternalism to patient autonomy to bureaucratic parsimony. Arch Intern Med 1985; 145(4): 713-715.

6. Szasz TS, Hollender MH. A contribution to the philosophy of medicine: the basic models of the doctor-patient relationship. Arch Intern Med 1956; 97(5): 585-592.

7. Marmor J. The feeling of superiority: an occupational hazard in the practice of psychotherapy. Am J Psychiatry 1953; 110: 370-376.

8. Tsai DF. How Should Doctors Approach Patients? A confucian reflection on personhood. J Med Ethics 2001; 27(1): 44-50.

9. Agarwal AK, Murinson BB. New dimensions in patient-physician interaction: values, autonomy, and medical information in the patientcentered clinical encounter. Rambam Maimonides Med J 2012; 3(3): e0017, doi: 10.5041/RMMJ.10085.

10. Veatch RM. A theory of medical ethics. New York: Basic Books Inc.; 1981: 327-330.

11. Burke G. Ethics and medical decision-making. Prim Care 1980; 7(4): 615-624. 
12. Jonsen AR, Siegler M, Winslade WJ. Clinical ethics: a practical approach to ethical decisions in clinical medicine. 7th ed. New York: McGraw Hill Inc.; 2010: 47-109.

13. Berg JW, Appelbaum PS, Lidz CW, et al. Informed consent: legal theory and clinical practice. 2nd ed. New York: Oxford University Press Inc.; 2001: 41-47.

14. Frankfurt HG. Freedom of the will and the concept of a Person. J Philos 1971; 68(1): 5-20.

15. Gorovitz S. Doctors' Dilemnas: moral conflict \& medical care. New York: Oxford University Press Inc.; 1982.

16. Sandel MJ. Liberalism and the limits of justice. New York: Cambridge University Press; 1982.

17. Macintyre A. After virtue: a study in moral theory. 3rd ed. Indiana: University of Notre Dame Press; 2007.

18. Emanuel EJ, Emanuel LL. Four models of the physician-patient relationship. JAMA 1992; 267(16): 2221-2226.

19. Quill TE, Brody H. Physician recommendations and patient autonomy: finding a balance between physician power and patient choice. Ann Intern Med 1996; 125(9): 763-769.

20. Ricoeur P. Decision making in medical and judicial judgments. In: Reflections on the just. Chicago: The University of Chicago Press; 2007.

21. Frankena W. Ethics. 2nd ed. New Jersey: Prentice-Hall Inc.; 1973: 47.

22. Emanuel EJ, Dubler N. Preserving the physician-patient relationship in the era of managed care. JAMA 1995; 273(4): 323-329.

23. Baudouin JL, Blondeau D. Ethique de la Mort et Droit à la Mort. Paris: Presses Universitaires de France; 1993: 23.

24. Egnew TR, Wilson HJ. Role modeling the doctor-patient relationship in the clinical curriculum. Fam Med 2011; 43(2): 99-105.

25. Charles C, Gafni A, Whelan T. Decision-making in the physician-patient encounter: revisiting the shared treatment decision-making model. Soc Sci Med 1999; 49(5): 651-661.

26. Bradley JG, Zia MJ, Hamilton N. Patient preferences for control in medical decision making: a scenario-based approach. Fam Med 1996; 28(7): 496-501.

27. Humphrey GB, Littlewood JL, Kamps WA. Physician/patient communication: a model considering the interaction of physicians' therapeutic strategy and patients' coping style. J Cancer Educ 1992; 7: 147-152.

28. Mansell D, Poses RM, Kazis L, et al. Clinical factors that influence patients' desire for participation in decisions about illness. Arch Intern Med 2000; 160(19): 2991-2996.

29. Murinson BB, Agarwal AK, Haythornthwaite JA. Cognitive expertise, emotional development, and reflective capacity: clinical skills for improved pain care. J Pain 2008; 9(11): 975-983.

30. Hesse BW, Nelson DE, Kreps GL. Trust and Sources of Health Information - the impact of the internet and its implications for health care providers: findings from the First Health Information National Trends Survey. Arch Intern Med 2005; 165(22): 2618-2624.

31. Scully C, Wilson N. Culturally sensitive oral health care. London: Quintessence Publishing Co. Ltd; 2006.

Tables: 2

Figures: 3

References: 31

Received: 09.03.2018

Reviewed: 21.05.2018

Accepted: 24.06.2018

Address for correspondence:

Antoine Aoun, MD, PhD

Family Medicine

Faculty of Nursing and Health Sciences

Notre Dame University - Louaize

Zouk Mosbeh

Lebanon

P.O.BOX: 72 Zouk Mikael

Tel.: +961 9218950 Ext: 5056

E-mail: aaoun@ndu.edu.lb 